\title{
UpPer Crossbeam of Free Forging Press Optimization in ORDER TO IMPROVE MECHANICAL PROPERTIES AND DURABILITY
}

\author{
Karel Raz ${ }^{\mathrm{a}}$, Milan Cechura ${ }^{\mathrm{b}}$, Zdenek Chval $^{\mathrm{a}}$ \\ ${ }^{a}$ University of West Bohemia, Faculty of Mechanical Engineering, Regional Technological Institute, Univerzitni 8, 306 \\ 14 Pilsen, Czech Republic \\ ${ }^{b}$ University of West Bohemia, Research Center of Forming Machines, Univerzitni 8, 30614 Pilsen, Czech Republic
}

\begin{abstract}
This paper deals with an analysis of the stress distribution in different design solutions of upper crossbeam of presses CKV type. Performed was design optimization in terms of minimum weight, maximum rigidity and uniformity of stress distribution in all sections. During optimization is considered the maximum force of technological operation upsetting. The performed optimization and reduction of the stress will improve the fatigue strength. It results also in increased lifetime. This whole process shows way of machine part design preparation.
\end{abstract}

Keywords: hydraulic press; FEM analysis; optimization; upper crossbeam; ribs design; stress; lifetime
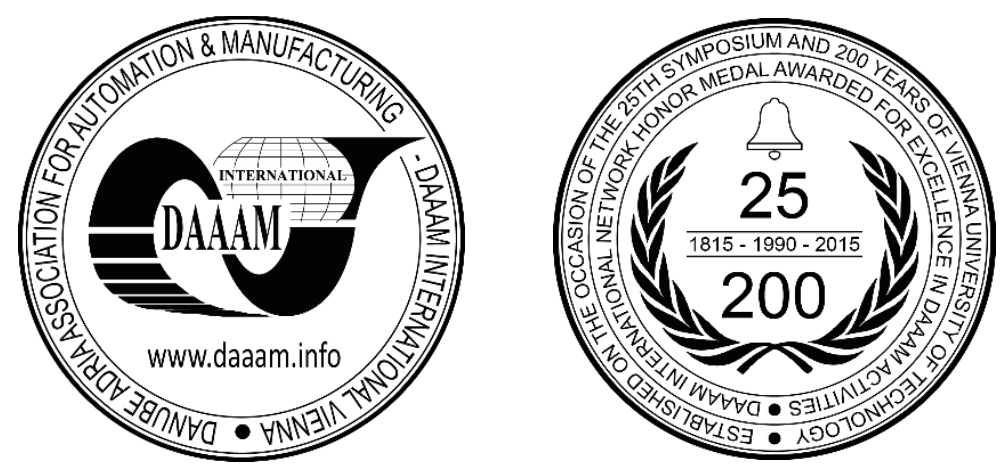

This Publication has to be referred as: Raz, K[arel]; Cechura, M[ilan] \& Chval, Z[denek] (2016). Upper Crossbeam of Free Forging Press Optimization in Order to Improve Mechanical Properties and Durability, Proceedings of the 26th DAAAM International Symposium, pp.0524-0529, B. Katalinic (Ed.), Published by DAAAM International, ISBN 9783-902734-07-5, ISSN 1726-9679, Vienna, Austria DOI: $10.2507 / 26$ th.daaam.proceedings.071 


\section{Introduction}

There are many ways how to increase lifetime of any machine. Short lifetime of some forging machines is a big problem. If we want improve design without weight increasing is necessary to perform design and shape optimization. The main aim of optimization is new structural design of whole machine or only of small part. This new design must have better stress distribution and all properties should be better. Removing of stress peaks leads to better dynamic properties and possibility of crack initiation is lower. From designers experience is obvious that is necessary to remove all sharp transitions in sections $[1,2]$.

In this problematic areas are higher stresses, lower fatigue limits and therefore minimal values of durability. Nowadays should be used virtual approach, if is during design process available. For simple parts can be used topological optimization and for complex shapes interpolation method in incriminated places.

A lot of software has today built-in modules that simplify the determination of the components lifetime. Our research center is focused now in optimizing individual parts or forging machines. New design of structural solutions should fully comply with the technical requirements. Producers want designs, where is minimized weight of the components and minimal stress in material.
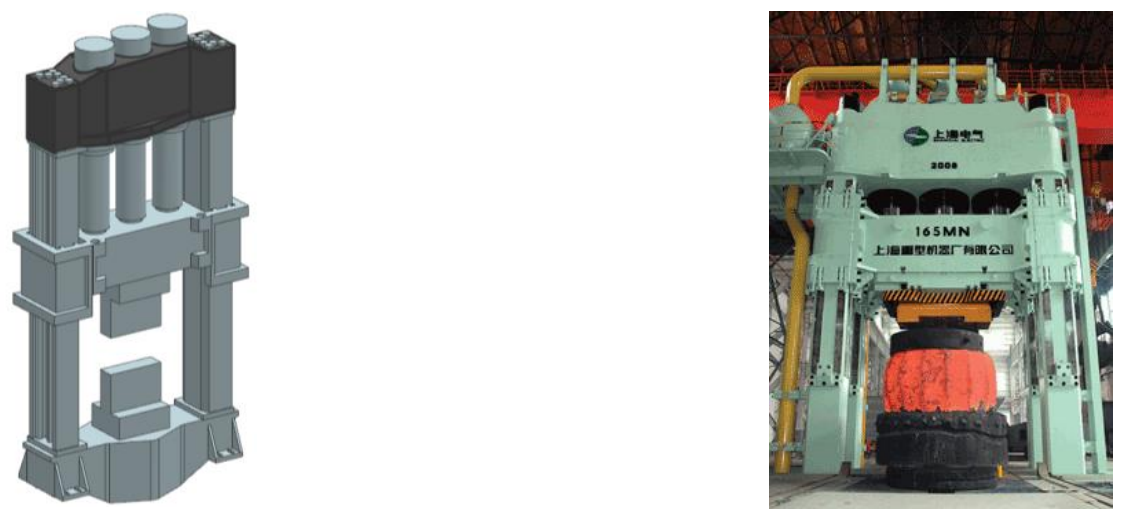

Fig. 1. CKV type of hydraulic press with marked upper crossbeam

On University of West Bohemia is performed monitoring of forming machines, and then after the virtual analysis is performed new optimized design.

The paper is intended to explain designers of forming machines how to perform optimization process. As an example is used upper crossbeam of hydraulic press. Same process should be used for other parts of this machine.

\section{Analysis and optimization of selected designs of upper crossbeams}

For optimization of four-column hydraulic press were considered only two mostly used designs of crossbeams.

Design 1- box- shaped casted part, from one piece

Design 2- box- shaped casted part, divided (number of divisions can be changed)

Design SD view

Table 1. Typical designs of casted crossbeams 


\subsection{Optimization of crossbeam- design 1}

Design 1 can be described as an upper crossbeam of press with maximal nominal force $90 \mathrm{MN}$. Total weight of crossbeam is $167 \mathrm{t}$.

First step of each optimization is simulation of existing design. In FEM simulation is considered only one half of crossbeam because is symmetric. This simulation model is loaded by maximal force from technological operation upsetting. Force of technological operation is found by simulation of upsetting in DEFORM 3D program. This simulation of technological operation in DEFORM 3D shows time dependent deformation of workpiece. This force of upsetting causes stress in material of crossbeam and deformation of whole machine. These values from simulation, also with weight, are compared with optimizes design $[3,4,5,6]$.

\begin{tabular}{lll}
\hline Parameter & $\begin{array}{l}\text { Existing } \\
\text { crossbeam }\end{array}$ & $\begin{array}{l}\text { Optimized } \\
\text { crossbeam }\end{array}$ \\
\hline Weight & $167 \mathrm{t}$ & $168 \mathrm{t}$ \\
Maximal displacement & $1,262 \mathrm{~mm}$ & $1,246 \mathrm{~mm}$ \\
Maximal stress in front wall & $68 \mathrm{MPa}$ & $57 \mathrm{MPa}$ \\
\hline
\end{tabular}

Table 2. Comparing of key parameters of optimized and existing solution

During optimization processes were removed critical areas of design. First of all were removed (by welding of steel plates) holes after mold cores. Next optimization step is removing of rib inside crossbeam (dark color). This rib does not have so big stress loading. The weight saved by removing of rib is used for increasing the thickness of the front wall of casting.

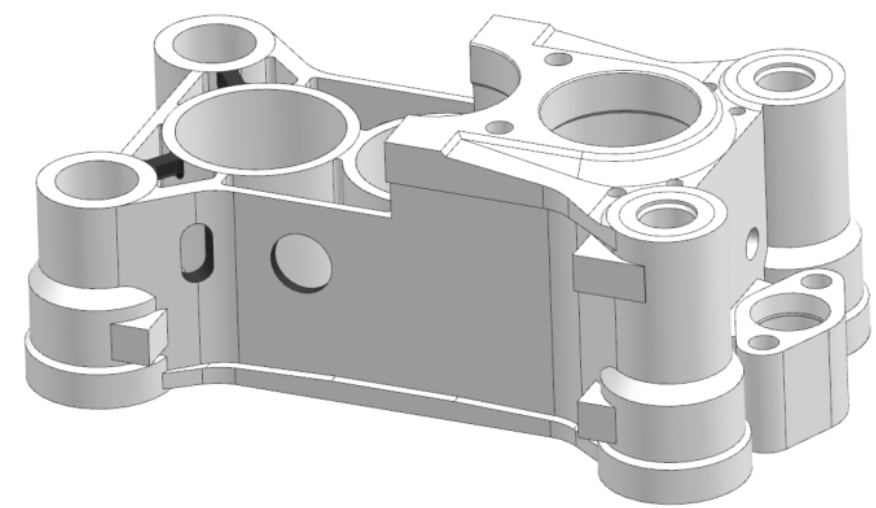

Fig. 2. Upper crossbeam with highlight of removed ribs and holes after casting cores
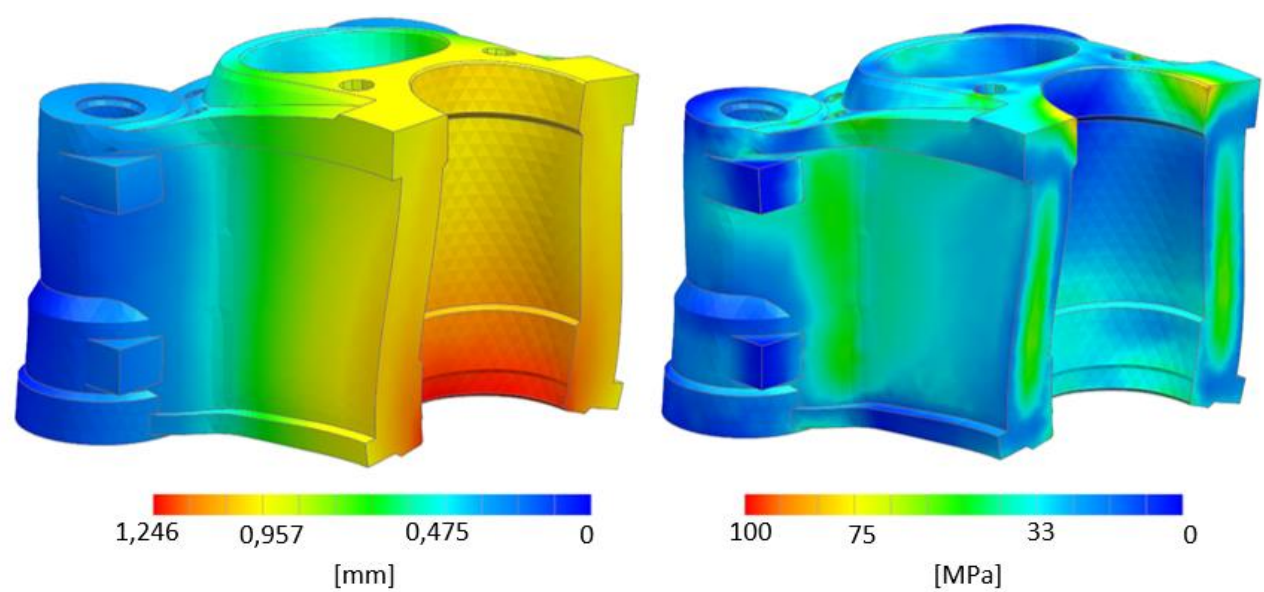

Fig. 3. Displacement $[\mathrm{mm}]$ and Von-Mises stress $[\mathrm{MPa}]$ in optimized design

\subsection{Optimization of crossbeam- design 2}

Design 2 can be described as an upper crossbeam of press with maximal nominal force $90 \mathrm{MN}$. Total weight of crossbeam is $131 \mathrm{t}$.

Simulation is defined same as on previous design. Again is simulated behavior of one half of crossbeam under upsetting load. 


\begin{tabular}{lll}
\hline Parameter & $\begin{array}{l}\text { Existing } \\
\text { crossbeam }\end{array}$ & $\begin{array}{l}\text { Optimized } \\
\text { crossbeam }\end{array}$ \\
\hline Weight & $131 \mathrm{t}$ & $132 \mathrm{t}$ \\
Maximal displacement & $1,919 \mathrm{~mm}$ & $1,803 \mathrm{~mm}$ \\
Maximal stress in main rib & $101 \mathrm{MPa}$ & $95 \mathrm{MPa}$ \\
\hline
\end{tabular}

Table 3. Comparing of key parameters of optimized and existing solution

During the optimization process was modified rib as is visible on the figure below. This rib in the existing design has direction from the columns to the center of the side cylinders. With respect to the loading was this rib modified. New design is from columns to the center of hydraulic press. This is better because forces are in direction corresponding to the force of technological operation.

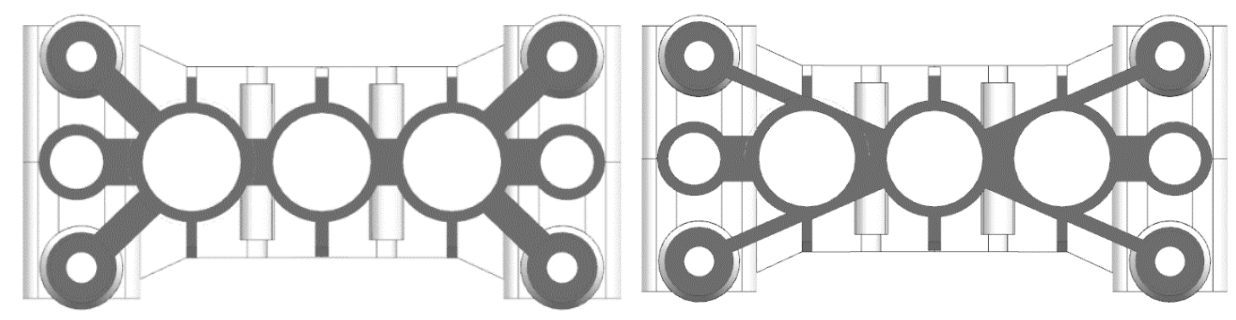

Fig. 4. Existing design and new design of ribs cylinder.

After optimization is value of maximal stress lower. New rib increased thickness of material close to the
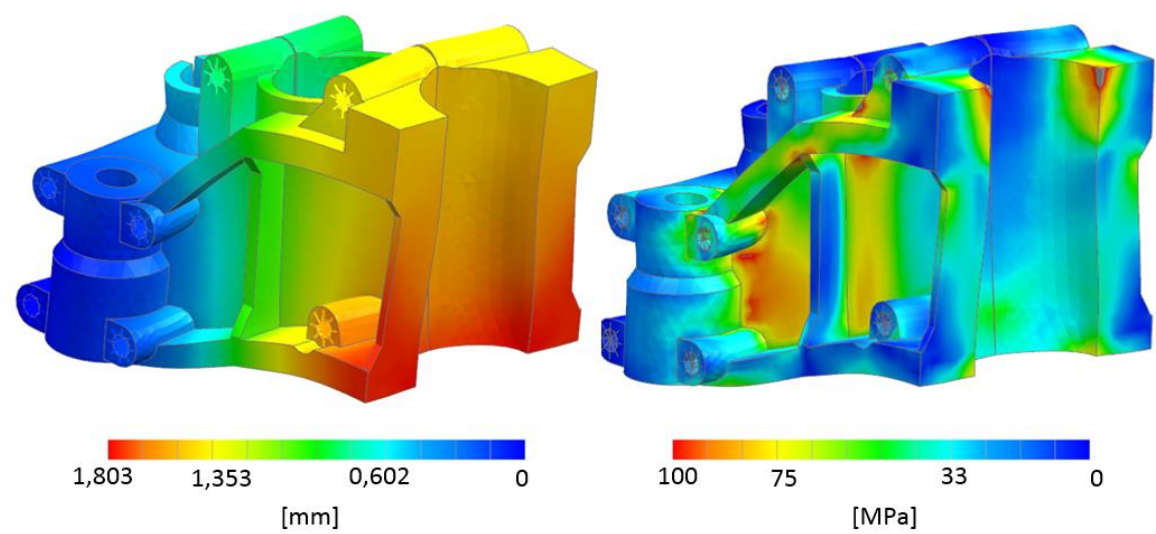

Fig. 5. Displacement $[\mathrm{mm}]$ and Von-Mises stress $[\mathrm{MPa}]$ in optimized design

Because this upper crossbeam is divided into two parts, it is important to determine the effect of new design on the opening of both parts. As seen in the figure, opening reaches $0,46 \mathrm{~mm}$.

Non-optimized original design reached a maximum value of opening $0,42 \mathrm{~mm}$. These values are in tolerance of FEM method and can be considered as same.

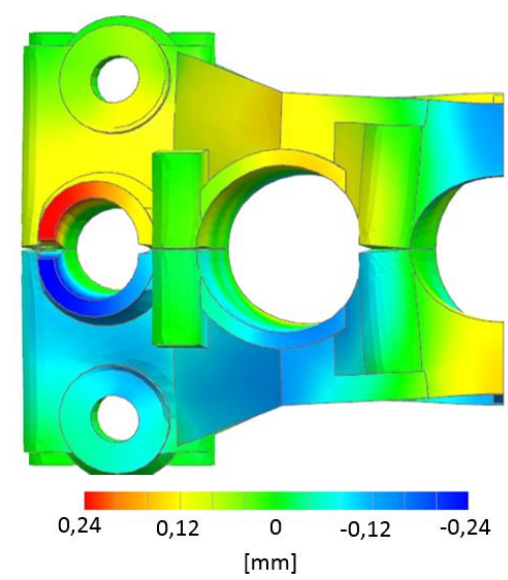

Fig. 6. Displacement $[\mathrm{mm}]$ in direction of opening 


\section{Influence on lifetime and operating properties} still same.

On selected upper crossbeam were done design changes, which lead to improving of properties when weight is

Both optimized variants have smaller deformation. Maximal value is up to 5\% smaller. This leads to accuracy increasing and lower energy consumption because stiffness of hydraulic press is higher.

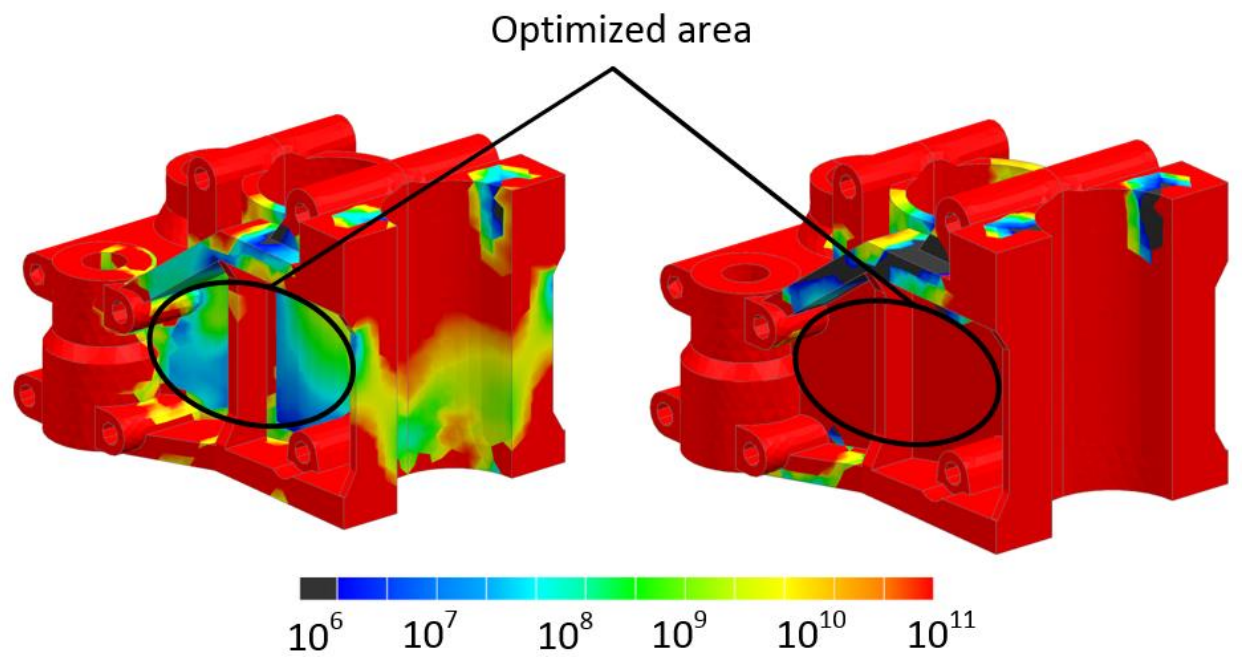

Fig. 7. Fatigue life on optimized area of crossbeam [cycles]

From stress point of view is optimized design more suitable for real forging, because Von-Mises stress in areas of interest is $10-15 \%$ smaller. Because hydraulic forging machines are working in factories more than 20 years, it is necessary to consider fatigue loading. Generally because is lower stress distribution, lifetime is higher. This stress distribution is decreasing possibility cracks initiation in material. In NX Nastran was performed simple fatigue calculation, as is visible on previous figure [7]. On optimized rib is maximal fatigue life more than 1011 cycles. Existing design has fatigue life in this are only around 107 cycles. A real value depends on real technological loading. This example is only for technological operation upsetting [8].

\section{Conclusion}

These results can be used for comparing of both designs of upper crossbeam. Each one has advantages and disadvantages. These can be summarized into:

Design 1- Upper crossbeam of press CKV with closed "case" design. It has better design, but it is harder to produce it. Also weight is $27 \%$ higher. Advantage is in non-divided design. Because of that is deformation only $50 \%$ comparing with divided design. Also maximal Von-Mises stress is $60 \%$ of value in divided design.

Design 2- Upper crossbeam of press CKV with opened "ribs" design. This design is easier to produce, because it doesn't need so many cores for casting and not so many holes for cores. This leads to uniform stress distribution. Disadvantage is higher stress value comparing to first design solution.

For smaller hydraulic presses, where is possible to produce casted parts as a non-divided castings is better to use design 1. For bigger machines is necessary to make divided crossbeam.

Optimization which is mentioned here is very simple example, how to follow procedure of optimization and implementation of it into design process. In design process should be this done in order to optimize design and improve lifetime. In future will be in our research center optimized all parts of hydraulic press in cooperation with producer of these machines. Also will be produced model of whole optimized press and measurement will be done.

\section{Acknowledgements}

The paper was supported by the "TA CR - project TE01020075" and project "Postdoc".

\section{References}

[1] J. Stanek, Basics of production machines design, University of West Bohemia, Pilsen, 2001.

[2] Company literature of TS Plzen a.s. 
[3] M. Zahalka, Modal Analysis of Hydraulic Press Frames for Open Die Forging, in DAAAM International Scientific Book 2013, pp. 1070-1075, Published by DAAAM International, ISBN 978-3-901509-94-0, ISSN 1726-9687, Vienna, Austria.

[4] H. Tschatsch, Metal Forming Practise: Processes - Machines - Tools, Springer-Verlag, Berlin, 2006.

[5] I. Piscan, T.Janssens, N.Predincea, Experimental Validation of FEM for Frictional Contacts, Annals of DAAAM for 2011 \& Proceedings of the 22nd International DAAAM Symposium, ISSN 1726-9679, ISBN 978-3-901509-834, Vienna, Austria, 2011, pp. 741-742.

[6] G. Dhondt, The Finite Element Method for Three-Dimensional Thermomechanical Application, John Willey\& Sons, Ltd., 2004.

[7] S. Benca, Nonlinear strength tasks solving with FEM, STU publishing, Bratislava, 2009.

[8] M. Cechura, V. Kubec, K. Raz, Dynamic behavior of the hydraulic press for free forging, in DAAAM International Scientific Book 2014, pp. 885-890, Published by DAAAM International, ISBN 978-3-901509-99-5, ISSN 18777058, Vienna, Austria. 